ISSN 0258-7122

Bangladesh J. Agril. Res. 36(1) : 51-62, March 2011

\title{
RICE PRODUCTION IN BANGLADESH EMPLOYING BY ARIMA MODEL
}

\author{
M. A. AWAL $^{1}$ AND M.A.B. SIDDIQUE ${ }^{2}$
}

\begin{abstract}
The present study was carried out to estimate growth pattern and also examine the best ARIMA model to efficiently forecasting Aus, Aman and Boro rice production in Bangladesh. It appeared that the time series data for Aus and Aman were $1^{\text {st }}$ order homogenous stationary but Boro was $2^{\text {nd }}$ order stationary. The study revealed that the best models were ARIMA $(4,1,4)$, ARIMA $(2,1,1)$, and ARIMA $(2,2,3)$ for Aus, Aman, and Boro rice production, respectively. The analysis indicated that short-term forecasts were more efficient for ARIMA models compared to the deterministic models. The production uncertainty of rice could be minimized if production were forecasted well and necessary steps were taken against losses. The findings of this study would be more useful for policy makers, researchers as well as producers in order to forecast future national rice production more accurately in the short run.
\end{abstract}

Keywords: Production, ARIMA model and forecasting of rice.

\section{Introduction}

Bangladesh is an agro-based developing country and still striving hard for rapid development of its economy. Agriculture is the mainstay of Bangladesh economy and it contributes about 22 percent of the gross domestic product (GDP). Approximately, 12 percent of GOP has been derived from crops while rice alone contributes 9.5 percent to the agricultural GDP (BBS, 2008). In Bangladesh, although 63 percent of the labour force is directly engaged in agriculture and 78 percent of total cropped area is devoted to rice production, the country is still suffering from a chronic shortage of foodgrain (BBS, 2008). Rice contributes more than 80 percent to the total food supply. More than $95 \%$ of population consumes rice and it alone provides $76 \%$ of calorie and $66 \%$ of total protein requirement of daily food intake (Bhuiyan et al., 2002). In fact, Agriculture sector is largely dominated by rice production. Growth in agriculture has tremendously centered on the expansion of modern rice production through investment in research and extension services. Rice, however, continues to remain main sources of food supply for the people of all the sectors. Rice in Bangladesh is grown in three distinct seasons, namely Boro (January to June), Aus (April to August), and Aman (August to December) covering almost 11.0

\footnotetext{
${ }^{1}$ Senior Scientific Officer, (Agricultural Economics), On-Farm Research Division, Bangladesh Agricultural Research Institute (BARI), Mymensingh and ${ }^{2}$ Senior Scientific Officer, Agricultural Economics Division, Bangladesh Rice Research Institute (BRRI), Gazipur 1701, Bangladesh.
} 
million hectares of land in Bangladesh (DAE, 2010), producing nearly 95 percent of the total food requirements, but there is still a need to increase production to feed the growing population which increases at the rate of 1.32 percent per annum (BER, 2010). However, the economic development of the country is fundamentally based on agriculture. It is often argued that the future development of the country depends predominantly on the sustainable development and utilization of the agriculture sector. The food problem is still one of the most vital aspects of economic development. It stands upon the rate and structure of economic growth, rate of inflation, poverty and nutrition, and the balance of trade and government's fiscal position.

Nevertheless, with the exploitation of full potentiality of rice production, the government of Bangladesh has to import huge amount of foodgrains from other countries through national and international agencies every year. Among the rice producing countries in Asia, Bangladesh occupies one of the lowest positions in rice production per hectare (WRS, 1995), Over the last three decades, the agricultural value added could not maintain pace with the population growth (BBS, 2008).

It is necessary to enhance the growth of rice production through increasing land productivity to meet the increasing food demand for the vast population of the country as the country has serious land constraints. Significant differences in rice productivity among the different regions are also barriers to the production growth (Hossain, 1990; Hossain and Ahamed, 1989). Many steps to enhance the growth are being taken from the part of the government and non-government agencies since the independence of the country. For future planning, it is necessary to evaluate the growth pattern of rice production that is achieved at the time in the country as a whole and also in the different varieties of the country. To reveal the growth pattern and to make best forecasts of Aus, Aman, and Boro rice in Bangladesh using appropriate time series models that can be able to describe the observed data successfully are necessary.

\section{Objectives}

The specific objectives of the present study are as follows:

i) to estimate the growth pattern of rice production of different seasons in Bangladesh;

ii) to develop appropriate ARIMA models for the time series of Aus, Aman, and Boro rice production in Bangladesh;

iii) to make five-year forecasts for all the time series with appropriate prediction interval; and compare the forecasting performance of ARIMA and deterministic models. 


\section{Methodology}

The present study was conducted mainly based on the secondary data. Majority of the information on the time series data of Aus, Aman, and Boro rice production pertaining to the period of 19972-73 to 2007-08 were generated and compiled from published volumes of Bangladesh Bureau of Statistics (BBS). lnferential statistical tools were employed in analyzing the data. In order to forecast the rice production was modeled by Box-Jenkins type stochastic autoregressive integrated moving average (ARIMA) process. The Box-Jenkins type ARIMA process (Box and Jenkins, 1978) can be defined as $\varnothing(B)\left(\Delta^{d} y_{t}-\mu\right)=$ $\theta(\mathrm{B}) \varepsilon_{\mathrm{t}}$. Here, $y_{t}$ denotes Aus, Aman, and Boro rice production in million metric tons, $\mu$ is the mean of $\Delta^{d} Y_{t}, \emptyset(B)$ is $1-\emptyset_{1} B---\emptyset_{p} B^{p}, \theta(B)$ is $1-\theta_{1} B----\theta_{q} B^{q}, \theta$ denotes the moving average parameter, $\varnothing$ denotes the autoregressive parameter, $p, q$, and $d$ denote the autoregressive, moving average and difference orders of the process, respectively, $\Delta$ and $B$ denote the difference and back-shift operators, respectively. The estimation methodology of the above model consists of three steps, namely identification, estimation of parameters, and diagnostic checking. The identification step involves the use of the techniques for determining the value of $\mathrm{p}, \mathrm{d}$, and $\mathrm{q}$. Here, these values are determined by using autocorrelation and partial autocorrelation functions (ACE and PACF) and Augmented DickeyFuller (ADF) test. The model used for ADF is $y_{-} y_{t}-1=\alpha+\beta t+(\rho-1) y_{t}-1+\lambda \Delta y_{t-1}$ (Pindyck and Rubinfeld, 1991, p.461).The second step is to estimate the parameters of the model. Here, the method of maximum likelihood is used for this purpose. The third step is to check whether the chosen model fits the data reasonably well. For this reason, the residuals are examined to find out if they are white noise. To test if residuals are white noise, the ACE of residuals and the Ljung and Box (1978) statistic are used. In case of two or more competing models passing the diagnostic checks, the best model is selected using the criteria multiple $\mathrm{R}^{2}$, Root Mean Squared Error (RMSE), Akaike Information Criterion (AIC), Bayesian Information Criterion (BIC), Mean Absolute Error (MAE), and Mean Absolute Percent Error (MAPE). Nine deterministic types' growth models are also considered in this study for comprising the forecasting efficiency of stochastic models. The above mentioned model selection criteria are used to select the best deterministic model forecasting purpose.

\section{Results and Discussion}

\section{Stationarity checking using ACF}

Auto correlation function is a very constructive tool to find out whether a time series is stationary or not. Both ACF and PACF are also used to determine autoregression and moving average orders of the models. All the figures represent 
that autocorrelations taper very slowly indicating that all the series are nonstationary. Now it is needed to take $1^{\text {st }}$ difference of all the time series and construct autocorrelation functions to examine whether they are stationary or not. The autocorrelation functions of $1^{\text {st }}$ differenced time series of Aus, Aman, and Boro rice, $2^{\text {nd }}$ differenced time series for Boro production are shown in Fig. 1 to and Fig. 7, respectively. The $1^{\text {st }}$ differenced time series seems to be stationarity, as the autocorrelation declines faster than that of undifferenced series.
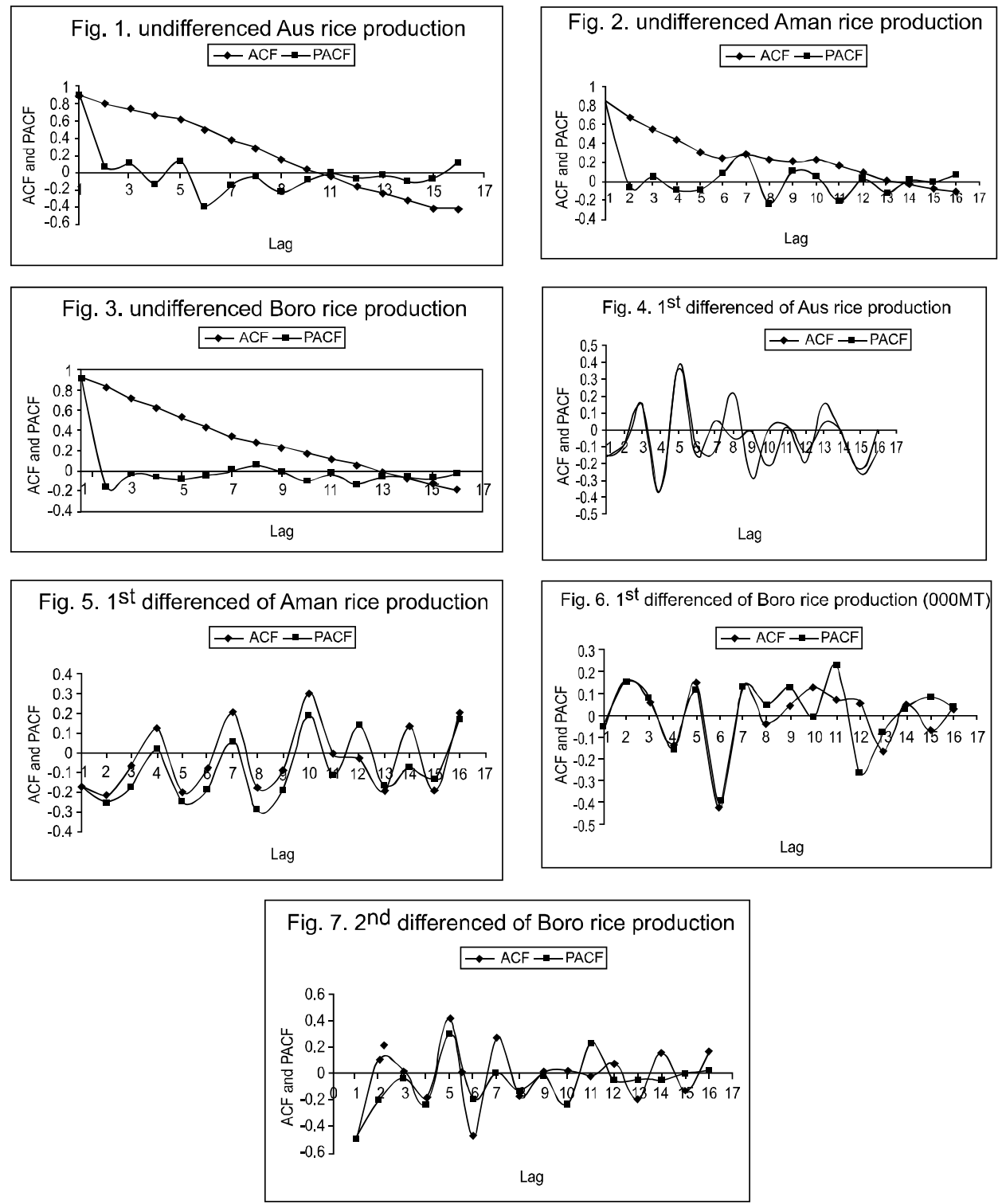
Now it is clear that ACFs of all the $1^{\text {st }}$ differenced series decline rapidly. So, it is revealed that Aus and Aman time series are stationary of order one but Boro time series is stationary of order two. Before taking decision about stationarity of the series, the study needs to carry out the formal ADF test of stationarity.

\section{Stationarity checking using ADF}

Apart from the graphical methods of using ACF for determining stationarity of a time series, a very popular formal methods of determining stationarity is the Augmented Dickey-Euller (ADF) test. Here, these tests were done for all the time series. The estimates of necessary parameters and related statistics for the time series of Aus, Aman and Boro rice production are presented in Table 1.

Table 1. ADF test of stationarity of Aus, Aman, and Boro rice production in Bangladesh.

\begin{tabular}{|c|c|c|c|c|c|c|c|c|c|c|}
\hline Area & Model & $\alpha$ & $\beta$ & $(\rho-1)$ & $\lambda$ & RSS & $\mathrm{DF}$ & DW & F & $F_{05,36}$ \\
\hline \multirow{4}{*}{ Aus } & Unrestricted & 934.13 & -21.45 & -0.24 & -0.08 & 4467475.02 & 30 & 1.43 & \multirow{4}{*}{2.10} & \\
\hline & S.Error & 436.60 & 7.73 & 0.12 & 0.19 & \multirow{3}{*}{5094348.09} & 32 & 1.38 & & \\
\hline & Restricted & -90.03 & & & -0.17 & & \multirow[t]{2}{*}{32} & \multirow[t]{2}{*}{1.38} & & \\
\hline & S.Error & 69.04 & & & 0.28 & & & & & \\
\hline \multirow{4}{*}{ Aman } & Unrestricted & 4234.11 & 116.39 & -0.77 & 0.19 & 15163525.60 & 30 & 2.02 & \multirow{4}{*}{7.30} & \\
\hline & S.Error & 1119.88 & 32.02 & 0.20 & 0.17 & & & & & 701 \\
\hline & Restricted & 180.12 & & & -0.17 & 22543833.24 & 32 & 2.14 & & \\
\hline & S.Error & 145.73 & & & 0.17 & & & & & \\
\hline \multirow{4}{*}{ Boro } & Unrestricted & -202.509 & 76.00 & -0.17 & -0.12 & 9684950.34 & 30 & 1.80 & \multirow{4}{*}{3.73} & \\
\hline & S.Error & 233.06 & 30.72 & 0.09 & 0.21 & \multirow{3}{*}{12099399.95} & \multirow{3}{*}{32} & \multirow{3}{*}{1.78} & & \\
\hline & Restricted & 318.798 & & & -0.06 & & & & & \\
\hline & S.Error & 124.146 & & & 0.19 & & & & & \\
\hline
\end{tabular}

The empirical analysis revealed that the hypothesis of random walk as underlies in the process of generating the time series is non-stationary and this can not be rejected, since the $\mathrm{F}$ statistics is insignificant at $5 \%$ level. So, all the undifferenced time series are non-stationary and they must be $1^{\text {st }}$ differenced to examine if $1^{\text {st }}$ differenced are non-stationary. 
Table 2. ADF test of stationarity of Aus, Aman, and Boro rice $1^{\text {st }}$ different production

\begin{tabular}{|c|c|c|c|c|c|c|c|c|c|c|}
\hline Area & Model & $\alpha$ & $\beta$ & $(\rho-1)$ & $\lambda$ & RSS & DF & DW & $\mathrm{F}$ & $\mathrm{F}_{05,36}$ \\
\hline \multirow{4}{*}{ Aus } & Unrestricted & 211.26 & -14.83 & -1.46 & 0.21 & 4163811.54 & 29 & 1.54 & \multirow{4}{*}{8.15} & \multirow{12}{*}{7.03} \\
\hline & S.Error & 153.45 & 6.95 & 0.41 & 0.27 & & 31 & 1.70 & & \\
\hline & Restricted & -38.30 & & & -0.51 & 6426307.48 & & & & \\
\hline & S.Error & 79.25 & & & 0.21 & & & & & \\
\hline \multirow{4}{*}{ Aman } & Unrestricted & 230.16 & 1.69 & -1.54 & 0.26 & 19615417.91 & 29 & 2.14 & \multirow{4}{*}{17.82} & \\
\hline & S.Error & 333.44 & 15.17 & 0.26 & 0.17 & & & & & \\
\hline & Restricted & 34.68 & & & -0.48 & 42929701.58 & 31 & 2.36 & & \\
\hline & S.Error & 204.97 & & & 0.15 & & & & & \\
\hline \multirow{4}{*}{ Boro } & Unrestricted & 27.025 & 16.419 & -1.091 & -.103 & 10573287.83 & 29 & 1.77 & \multirow{4}{*}{6.37} & \\
\hline & S.Error & 248.79 & 13.34 & 0.32 & 0.22 & & & & & \\
\hline & Restricted & -0.81 & & & -0.66 & 15067161.91 & 31 & 2.11 & & \\
\hline & S.Error & 121.44 & & & 0.16 & & & & & \\
\hline \multicolumn{11}{|c|}{$2^{\text {nd }}$ different Boro } \\
\hline \multirow{4}{*}{ Boro } & Unrestricted & 161.08 & -7.78 & -2.196 & 0.347 & 13394657.12 & 28 & 1.86 & \multirow{4}{*}{20.04} & \multirow[t]{2}{*}{$\mathrm{F}_{05,34}$} \\
\hline & S.Error & 297.823 & 13.244 & 0.36 & 0.20 & & & & & \\
\hline & Restricted & -61.43 & & & -0.75 & & 30 & 2.48 & & 7.05 \\
\hline & S.Error & 180.67 & & & 0.14 & 31294687.49 & & & & \\
\hline
\end{tabular}

The ADF test for the $1^{\text {st }}$ differenced time series of Aus, Aman, and Boro rice production are presented in Table 2. The test analysis illustrated that Aus and Aman rice production, the $1^{\text {st }}$ differenced time series are stationary since the $\mathrm{F}$ statistics are significant at $5 \%$ level, but Boro rice production is not stationary. So, Boro time series need to be difference to $2^{\text {nd }}$ examine stationary of the series. The analysis showed that Boro time series are stationary at $5 \%$ level of significance. The ACFs and ADF test indicated that Aus and Aman time series are stationary of order one and Boro time series is stationary of order two.

\section{Aus rice productions}

The ACF and PACE of Aus time series data as shown in Fig. 4 indicated that the autoregressive and moving average orders can not be more than 5 , since the ACF declines significantly after the 5 lag and PACF food declines significantly after the $1^{\text {st }}$ lag and there is no significant spikes in both the functions. So, the tentative specifications of the model may be ARIMA $(4,1,0)$, ARIMA $(4,1,1)$, ARIMA (4,1,4), ARIMA (4,1,3), ARIMA (5,1,1), ARIMA (5,1,2), ARIMA(5,1 ,0), ARIMA (5,1,3), and ARIMA $(5,1,5)$. All these models are estimated and their diagnostic checks are done using ACFs of residuals and Ljung and Box 
chisquares test. In addition, model selection criteria $\mathrm{R}^{2}$, RMSE, AIC, BIC, MAE, and MAPE are used to select the best model. The value of chi-square with the Pvalue and the values of model selection criteria are presented in Table 5 only for the best model. It was found that the best ARIMA specification for Aus rice production is ARIMA $(4,1,1)$ model with estimated parameters, standard errors: $t$ and $\mathrm{P}$-values are presented below:

$$
\begin{aligned}
& \left(1+0.56 \mathrm{~B}+0.11 \mathrm{~B}^{2}-0.017 \mathrm{~B}^{3}+0.42 \mathrm{~B}^{4}\right)\left(\Delta \mathrm{Y}_{\mathrm{t}}-34.24\right)=(1+0.73 \mathrm{~B}) \varepsilon_{\mathrm{t}} \\
& \mathrm{SE}=\left(\begin{array}{lllll}
0.20) & (0.20) & (0.19) & (0.17) & (30.10)
\end{array}\right) \\
& \mathrm{t}=(-2.77)(-0.56)(0.0 .08)(-2.39)(-1.13)(-4.05)
\end{aligned}
$$

According to the model selection criteria, the cubic model can be considered as the best deterministic model for Aus rice production. It denoted that the growth rate of Aus rice production was not constant during the study period. The estimated model with necessary statistics is as follows:

$Y=2158.01+230.12 \mathrm{t}-15.32 \mathrm{t}^{2}+0.24 \mathrm{t}^{3}$

$\mathrm{SE}=(180.46) \quad(41.66)(2.59) \quad(0.04)$

$\mathrm{t}=(11.95) \quad(5.52) \quad(-5.59) \quad(5.21)$

\section{Aman rice production}

The ACF and PACF of the $1^{\text {st }}$ differenced of Aman rice production as shown in Fig. 5 is similar to those for $1^{\text {st }}$ differenced of Aus rice production. So, the same tentative specifications are considered for Aman rice production. It appeared from the analysis that the specification ARIMA $(2,1,1)$ is the best. The chi-squre tests for diagnostic checking for this model can be viewed in Table 5 . The estimated models with necessary statistics are presented below:

$\left(1-0.43 B+0.17 \mathrm{~B}^{2}\right)\left(\Delta \mathrm{Y}_{\mathrm{t}}-144.68\right)=(1-0.95 \mathrm{~B}) \mathcal{E}_{t}$

$\mathrm{SE}=\quad(0.20) \quad(0.38) \quad(18.06) \quad(0.25)$

$\mathrm{t}=\quad(2.11) \quad(-0.88)(8.01) \quad(3.68)$

According to the model selection criteria the exponential model can be considered as the best deterministic model for Aman rice production in Bangladesh. The estimated model with necessary statistics is as follows:

$\mathrm{Y}_{\mathrm{t}}=5879.350+0.017 \mathrm{t}$

$\mathrm{SE}=(184.175) \quad(0.001)$

$\mathrm{t}=(31.92) \quad(11.96)$

\section{Boro rice productions}

The ACF and PACF of the $1^{\text {st }}$ differenced of Boro rice production as shown in Fig. 6 revealed that all the autocorrelations are too small and the Box and Ljung 
test find all autocorrelation are insignificant. So, the best model for Boro rice production is ARIMA $(2,2,3)$. The chi-square tests for residual and the value of model selection criteria $\mathrm{R}^{2}$, RMSE, AIC, BIC, MAE, and MAPE can be viewed in Table 3. The estimated models with necessary statistics are presented below:

$$
\begin{aligned}
& \left(1+1.69 \mathrm{~B}+0.87 \mathrm{~B}^{2}\right)\left(\Delta^{2} \mathrm{Y}_{\mathrm{t}}-16.94\right)=\left(1+0.81 \mathrm{~B}-0.81 \mathrm{~B}^{2}+0.67 \mathrm{~B}^{3}\right) \\
& \mathrm{SE}=\quad(014) \quad(0.129) \quad(12.69) \quad(0.24) \quad(0.29) \quad(0.27) \\
& \mathrm{t}=(-11.72)
\end{aligned}
$$

The best deterministic model for Boro rice production is the Quadratic model presented bellow:

$$
\begin{aligned}
& \mathrm{Y}=2027.37-63.51 \mathrm{t}+10.62 \mathrm{t}^{2} \\
& \mathrm{SE}=(309.32) \\
& \mathrm{t}=(6.55)
\end{aligned}
$$

\section{Diagnostic checking}

For diagnostic checking, the ACF of residuals and Ljung and Box chi-square statistics are widely used in practice. The chi-square statistics are presented in Table 3 for all best selected stochastic models with P-values. All the chi-square values are insignificant. It implied that the residuals of the respective time series are white noise implying that the model fitness is acceptable. The estimated values of other model selection criteria for both best selected stochastic and deterministic models are also shown in Table 3. The table revealed that ARIMA models are superior to the respective deterministic models.

Table 3. Diagnostic tools and model selection criteria for the best fitted models.

\begin{tabular}{l|c|c|c|c|c|c|c|c|c}
\hline Area & Model & $\mathrm{R}^{2}$ & RMSE & AIC & BIC & MAE & MAPE & $\begin{array}{c}\chi^{2} \text { (BL at } \\
16 \text { lag })\end{array}$ & $\begin{array}{c}\text { P- } \\
\text { value }\end{array}$ \\
\hline Aus & $\begin{array}{l}\text { ARIMA } \\
(4,1,1)\end{array}$ & 086 & 205.50 & 384.78 & 394.11 & 154.04 & 6.37 & 9.11 & 0.91 \\
& $\begin{array}{l}\text { Cubic } \\
\text { Aman }\end{array}$ & 085 & 311.6 & 421.40 & 427.73 & 264.51 & 11.64 & & \\
& $\begin{array}{l}\text { ARIMA } \\
(2,1,1)\end{array}$ & 0.84 & 601.04 & 477.90 & 475.38 & 500.52 & 6.55 & 6.48 & 0.98 \\
& $\begin{array}{l}\text { Exponential } \\
\text { Boro }\end{array}$ & 0.81 & 721.37 & 479.84 & 481.01 & 566.27 & 7.16 & & \\
$\begin{array}{l}\text { ARIMA } \\
(2,2,3)\end{array}$ & 0.98 & 511.68 & 436.16 & 445.32 & 350.26 & 8.18 & 15.93 & 0.45 \\
& Quadratic & 0.97 & 559.71 & 461.57 & 466.32 & 443.89 & 8.95 & & \\
\hline
\end{tabular}




\section{Forecasting}

Five years' forecasts of Aus, Aman, and Boro production are estimated using the best selected models and are presented in Table 4, 5, and 6, respectively. Prediction intervals of forecast are also presented.

Table 4. Aus rice production forecast.

\begin{tabular}{c|c|c|c|c|c|c}
\hline \multirow{2}{*}{ Year } & \multicolumn{3}{|c|}{ ARIMA (4,1,1) } & \multicolumn{3}{c}{ Cubic } \\
\cline { 2 - 7 } & Forecast & LPL & UPL & Forecast & LPL & UPL \\
\hline $2008-09$ & 1735.65 & 1300.65 & 2170.65 & 1896.07 & 1279.51 & 2512.62 \\
$2009-10$ & 1686.78 & 1008.00 & 2365.56 & 1993.13 & 1324.71 & 2661.56 \\
$2010-11$ & 1658.29 & 847.70 & 2468.88 & 2114.47 & 1379.58 & 2849.36 \\
$2011-12$ & 1620.12 & 664.84 & 2575.40 & 2261.52 & 1444.71 & 3078.32 \\
$2012-13$ & 1599.80 & 593.60 & 2605.99 & 2435.72 & 1521.04 & 3350.39 \\
\hline
\end{tabular}

The empirical analysis illustrated that short-term forecasts are more efficient for ARIMA models compared to the deterministic models. In case of Aus rice production, cubic model forecast is higher compared to the ARIMA model, but MAPE (11.64\%) of cubic model is higher than MAPE (6.37\%) ARIMA model. Less MAPE (\%) provided more accurate results than higher MAPE (\%). So, ARIMA model produced more accurate results than deterministic model. However, the ARIMA model estimated that the Aus rice production 1735 thousand metric tons in 2008-09 and if the present Aus rice production continues the Aus rice production of Bangladesh would be 1591 thousand metric tons in the year 2012-2013.

Table 5. Aman rice production forecast.

\begin{tabular}{c|c|c|c|c|c|c}
\hline \multirow{2}{*}{ Year } & \multicolumn{3}{|c|}{ ARIMA (2.1.1) } & \multicolumn{3}{c}{ Exponential } \\
\cline { 2 - 7 } & Forecast & LPL & UPL & Forecast & LPL & UPL \\
\hline $2008-09$ & 11056 & 9476 & 12636 & 11305 & 9278 & 13774 \\
$2009-10$ & 11124 & 9319 & 12928 & 11506 & 9435 & 14031 \\
$2010-11$ & 11293 & 9467 & 13119 & 11711 & 9595 & 14294 \\
$2011-12$ & 11461 & 9631 & 13291 & 11920 & 9756 & 14563 \\
$2012-13$ & 11612 & 9772 & 13452 & 12133 & 9920 & 14837 \\
\hline
\end{tabular}

Table 3 indicated that Exponential model produced higher AIC(480), BIC(481), RMS(721), MAPE(566), and MAE (7.16) compared to ARIMA $(2,1,1)$. Therefore, ARIMA Model is more appropriate for forecasting compared to deterministic model. The ARIMA model forecasted that the Aman rice production is 11056 thousand metric tons in 2008-09 and if the present Aman 
rice production continues the Aman rice production of Bangladesh would be 11612 thousand metric tons in the year 2012-2013.

Table 6. Boro rice production forecast.

\begin{tabular}{c|c|c|c|c|c|c}
\hline \multirow{2}{*}{ Year } & \multicolumn{3}{|c|}{ ARIMA (2.2.3) } & \multicolumn{3}{c}{ Quadratic } \\
\cline { 2 - 7 } & Forecast & LPL & UPL & Forecast & LPL & UPL \\
\hline $2008-09$ & 13538 & 12399 & 14677 & 14229 & 12883 & 15575 \\
$2009-10$ & 13809 & 12051 & 15567 & 14963 & 13582 & 16343 \\
$2010-11$ & 14450 & 12252 & 16648 & 15718 & 14297 & 17139 \\
$2011-12$ & 15323 & 12493 & 18154 & 16494 & 15027 & 17961 \\
$2012-13$ & 15541 & 12275 & 18807 & 17291 & 15772 & 18811 \\
\hline
\end{tabular}

Deeply observing the forecasted values and confidence intervals presented in Table 6 reveal that forecasting error sufficiently small and consequently the intervals are too large. The forecasting found that If the existing Boro rice production continues, Bangladesh would obtain 13538 thousand metric tons in the year 2008-09 and it would increase 15541 thousand metric tons in the year of 2012-13. Therefore, the Government of Bangladesh should take input subsidiary policy for the increase of productivity of this crop. The production uncertainty of Boro rice was minimized if prices were forecasted well ahead so that necessary step could be taken against losses.

\section{Conclusion}

This study made the best effort to develop a short run forecasting model of rice production in Bangladesh. The empirical analysis indicated that ARIMA $(4,1,1)$, $\operatorname{ARIMA}(2,1,1)$, and $\operatorname{ARIMA}(2,2,3)$ were best fitted model for short run forecasting of Aus, Aman, and Boro rice production, respectively. However, the ARIMA model estimated that the rice production of Bangladesh were 1735, 11056, and 13538 thousand metric tons in 2008-09 and if the trend in present rice production to be continued, the total rice (Aus, Aman, and Boro) production of Bangladesh would be 1591, 11612, and 15541 thousand metric tons in the year 2012-2013. To increase rice production of Bangladesh, the government should put emphasis on adopting of high yielding rice varieties in three rice seasons and take proper input subsidiary programme in order to achieve food security. The production uncertainty of rice could be minimized if production were forecasted well and necessary steps were taken against losses. For this purposes, the findings of this study would be more useful for policy makers, researchers, and producers for future national rice production policies. 


\section{References}

Akaike, H. 1973. Information, Theory And Extension of the Maximum Likelihood Principal, In: Second International Symposium. Information, B. N. Petroc and F. Caski, eds., Budapest. pp.25-129.

Akter, M and W. M. H. Jaim .2002.Changes in the major foodgrains production in Bangladesh and their sources during the period from 1979/80 to 1998/99. The Bangladesh Journal of Agricultural Economics 25 (1):1- 16.

Barua, P. and S. Alam .2000.Growth, price instability and flexibility of major crops un Bangladesh. The Bangladesh Journal of Agricultural Economics 23 (1\&2):103- 114.

Bangladesh. Bureau of Statistics (BBS). 2008, Bangladesh Population Census, Statistics Division, Ministry of Planning, Government of the People's Republic of Bangladesh, Dhaka.

Bangladesh Economic Review (BER), 2010, Department of Finance, Ministry of Finance, Government of the People's Republic of Bangladesh, Dhaka.

Bhuiyan, N. I., D. N. R. Paul and M. A. Jabber. 2002. Feeding the extra millions by 2025- Challenges for rice research and extension in Bangladesh, National Workshop on Rice Research and Extension in Bangladesh, Bangladesh Rice Research Institute, Gazipur, 29-3 1 January.

FAO. 1984. FAO Production Year Book. 1983, Vol. 37, Food and Agricultural Organization of United States, Rome.

Granger, C. W. T. and P. Newbold.1986. Forecasting Economics Time Series, Second Edition, Academic Press, Inc., Orlando, Florida.

Gujarati, D. N., 2003. Basic Econometric, Fourth Edition, MeGraw-Hill Inc., New York. pp.23- 26.

Haque, M. E., M. I. Hossain and K. M. M. Rahman. 2004. Searching for the best fitting deterministic model for innovative growth analysis and forecasting of rice production in Bangladesh. The Bangladesh Journal of Agricultural Economics. 27(1):1 5-35.

Haque, M. E., M. I. Hossain and M. F. Imam. 2005. The best fitting model for growth analysis and forecasting of fish production in Bangladesh. J. Bangladesh Soc. Agric. Sci. Technol. 2(1\&2):227-234.

Hossain, M. 1980. Foodgrain Production in Bangladesh: Performance, potential and Constraint. The Bangladesh Development Studies 8(1\&2): 39-70.

Hossain, M. 1984. Increasing food availability in Bangladesh: Constraints and possibilities. A report prepared for the Ministry of Agriculture, Government of the People's Republic of Bangladesh, and ILO, Geneva.

Jabber, M. A. and R. P. Jones.1997. The growth of MV rice production and adoption in Bangladesh. The Bangladesh Journal of Agricultural Economics 20(2): 1-19.

Johnston, J. 1984, Econometric Methods, Third Edition, MoGraw-Hill Inc, New York. 
Mahmud, W. and Muqtada.1983. Institutional factors and technological Innovate. The case of HYV rice in Bangladesh, ILO World Employment Program, Staff working.

Pindyck, R. L. and D. L. Ribinfeld.1991. Econometric models and Economic Forecasts, Third Edition, McGraw-Hill Inc., New York. pp230-461.

Schwarz, G. 1978. Estimating the dimension of a model. Annals of Statistics 6: 461-464.

World Rice Statistics (WRS). 1995. International Rice Research Institute, Manila 1099, Philippines. 